\title{
Banker Compensation and Bank Risk Taking: The Organizational Economics View
}

\author{
Arantxa Jarque and Edward Simpson Prescott* \\ Federal Reserve Bank of Richmond
}

September 9, 2013

\begin{abstract}
A multi-agent, moral-hazard model is used to analyze how to regulate compensation of bank employees below a CEO in order to limit bank risk. Unlike in the single-agent model, pay for performance does not necessarily create risk. If employee returns are uncorrelated, pay is irrelevant for risk. If returns are correlated, a low wage can indicate risk. If correlation is endogenous, relative-performance contracts that encourage correlation of returns can create risk. A sufficient condition for compensation to induce bank risk is provided. A loan review function is added; evaluating bank controls is identified as an alternative means for limiting risk.
\end{abstract}

Keywords: incentive compensation, relative performance, bank regulation, controls JEL Codes: D82, G21, G28, J33

${ }^{*}$ Earlier versions of this paper were presented at the Bank of Canada, the Federal Reserve Bank of St. Louis, the 2010 Econometric Society World Congress, the 2010 SAET meetings, and the 2013 Conference on Tournaments, Contests, and Relative Performance Evaluation. We would like to thank Joe Haubrich for helpful comments. The views expressed here are those of the authors and not necessarily those of the Federal Reserve Bank of Richmond or the Federal Reserve System. 


\section{Introduction}

This paper uses organizational economics to analyze the connection between banker compensation and bank risk. In a framework where a bank operates under limited liability with deposit insurance, a sequence of multi-agent, moral-hazard models is developed. Contracts that implement both safe and risky lending decisions by a bank's employees are provided. These contracts are then used to address the question of what characteristics of compensation arrangements encourage risk-taking behavior.

Controlling bank risk via regulation of compensation arrangements is a new focus of bank regulation. The Federal Reserve Board in 2010 issued supervisory guidance to banks that their compensation arrangements "Provide employees incentives that appropriately balance risk and reward" (Federal Register, 2010). Similarly, the Dodd-Frank law requires that regulations be written that prohibit incentive-based compensation that encourages inappropriate risks. ${ }^{1}$ These regulations are motivated by the belief that bank compensation practices were a significant contributory factor to the recent financial crisis (e.g., Financial Stability Forum (2009)).

Conceptually, there are two classes of people in a bank who could materially contribute to the risk of a bank. The first is an individual, like a CEO or some traders, whose individual decisions can materially affect the bank's performance. The second is a group of individuals like loan officers whose decisions together can have a significant impact on the bank's performance.

This paper analyzes the second class of people. We do this for two reasons. First, a CEO is limited in his ability to directly control the actions of his subordinates. Instead, he has to rely on indirect methods, such as delegation of authority, usage of internal controls, and compensation to direct the actions of subordinates. In the end, a bank's risk profile is determined by the actions of its lending officers and other employees. Second, despite the high level of CEO pay, by far most labor compensation paid out by a bank goes to its other employees, so compensation regulations have the largest effect on them. For example, the largest bank holding company in the United States is J.P. Morgan. As of December 31,

\footnotetext{
${ }^{1}$ There is a precedent in that the Federal Deposit Insurance Corporation Improvement Act of 1991 gives bank supervisors authority to prevent banks from paying "excessive" compensation, but this feature of the Act is not directly connected with bank risk taking.
} 
2012, it had 248,633 employees, measured at full time equivalents, and paid them 31 billion dollars in salaries and benefits (source: FR Y-9C). Meanwhile, its CEO was paid 18.7 million dollars (source: Execucomp), a very small fraction of total compensation.

Our approach is to develop multi-agent, moral-hazard models where bank equity owners may like risk, but risk-averse employees are the agents that make the decisions that determine bank risk. This class of models has three features that characterize large banks. First, large banks benefit from explicit and implicit government insurance of their liabilities, so the equity owners do not bear all the costs of a bank failure. Second, in large banks there are many employees, most of whom alone have a minuscule effect on the performance and risk of the bank. Third, most activities involve some degree of monitoring and supervision by other employees. For example, loan review is often performed by someone who did not originate a loan. Similarly, control functions like compliance, risk management, and audit are separate departments that assess whether employees are following bank policies.

Modeling a bank as an organization has strong implications for the connection between employee compensation and bank risk, implications that differ from that for a CEO. The first implication is that because each loan officer has an infinitesimal effect on the performance of a bank, bank risk is determined by the correlation of loan officers' returns. When correlation is endogenously determined through loan officers' actions, how compensation is tied to the performance of the entire bank - a form of relative performance - is what determines risk. Paying the loan officer a bonus for good performance that increases with bank performance encourages correlated lending decisions. Conversely, reducing the bonus as bank performance improves encourages uncorrelated lending decisions.

Correlation is so important for determining bank risk that when it is exogenous, that is, when loan officer actions do not affect the correlation of their returns, the implications from the single-agent model can be completely reversed. For example, we show that when loan officer returns are perfectly uncorrelated, there is no bank risk because the loan officer risk is entirely idiosyncratic and averages out. Consequently, compensation is irrelevant for bank risk, though it may matter for bank profits and it certainly matters for the risk of a loan officer's return. We also show that when loan officer returns are perfectly correlated, loan officer effort can be perfectly inferred from bank output, so there is no moral hazard problem and the officer can be paid a wage. Here, the correlation in returns means that there is a 
lot of risk for the bank and it can be shown, under reasonable conditions, that a low wage creates more risk than a high wage.

The second implication of the organizational view is that there are alternatives to regulating compensation. Lending and other activities, like trading, are monitored by banks and subject to limits and other controls. We provide a model where loans originated by one group of agents are reviewed by a second group of agents who decide whether to accept or reject them. We examine the role of compensation in this model, but also show how evaluation of the performance of the loan review function can determine whether loan review is properly limiting the correlation of bank returns.

One feature of compensation that we do not consider is how the timing of payments to bankers affects bank risk. The timing of compensation is important, partly because regulations are pushing banks to use more deferred compensation that can be "clawed back," that is, reduced if the loan or project performs badly in the long run. We leave this feature out, however, to focus on the connection between compensation and correlation of returns. For work addressing the timing question using dynamic moral-hazard models with persistence, see Jarque and Prescott (2010).

Section 2 reviews the literature on banker compensation. Section 3 develops a multiagent moral-hazard model where each agent has a small effect on the bank's total return. Section 4 analyzes the importance of correlation in returns. Section 5 adds studies monitoring and bank controls by adding a second group of agents who review and assess loans produced by the first group. Section 6 concludes.

\section{Literature}

There are two theoretical literatures relevant for this paper. The first one is the literature about the incentives of a bank to make inefficient investments. Both Merton (1977) and Kareken and Wallace (1978) showed that, due to deposit insurance, banks have incentives to take risky investment decisions in order to receive implicit transfers from the deposit insurer. The large number of thrift failures in the U.S. S\&L crisis of the 1980s is often considered to be strong evidence of these incentives at work (e.g., White (1991)).

Much of the resulting theoretical banking literature on risk shifting incentives has focused 
on the use of capital requirements or franchise value to mitigate this distortion. Examples of papers along this line include Flannery (1989), Furlong and Keeley (1990), and Kim and Santomero (1988). ${ }^{2}$ In this theoretical literature, management is implicitly assumed to act in the interests of bank equity owners.

The second relevant literature assumes that management does not necessarily act in the interests of bank equity owners. Jensen and Murphy (1990) is an early example of this problem. However, only a few papers such as John, Saunders, and Senbet (2000), Phelan (2009), and Bolton, Mehran, and Shapiro (2010) explicitly study this problem in the context of banking. Furthermore, in all three of these papers a single agent chooses bank risk, which is appropriate for studying CEO compensation, but as we will show, not appropriate for studying compensation of lower level employees.

In contrast, the empirical literature on compensation and risk shifting in banking is bigger, but almost all of it looks at CEO compensation, mainly because of data availability. One portion of this literature analyzes data from the 1980s and early 1990s, when there were banking problem in the U.S. These papers often looked at proportions of pay that are variable, e.g., equity based, and examined whether this is correlated with bank risk. Their findings were mixed. For example, Houston and James (1995) studied commercial bank CEO pay from 1980-1990 and found that CEO compensation policies did not encourage excessive risk taking in the 1980s. In contrast, Benston and Evans (2006) looked at a sample of highly levered banks over the period 1988-1994 and found evidence of more use of short-term compensation, like bonuses, at banks that failed. Using bank CEO data from 1976-1988, Crawford, Ezzell, and Miles (1995) found some mixed evidence that highly levered banks increased incentives for their CEOs, which is consistent with risk shifting.

Another portion of this literature looks at a sample period that includes the recent financial crisis. Fahlenbrach and Stulz (2011) investigate whether the performance of banks during the crises is related to incentives provided for their CEOs in the period leading up to it. They find some evidence that banks with CEOs whose objectives were better aligned with the interests of shareholders performed worse than other banks. Cheng, Hong and Scheinkman (2010) find important and persistent differences across firms in the level of pay

\footnotetext{
${ }^{2}$ Marshall and Prescott $(2001,2006)$ extend this work to allow more complicated capital structures that include warrants and convertible debt.
} 
and risk, with firms that took more risk also having the highest pay. Moreover, they find that the firms that take more risks performed worse during the crisis period. The authors also interpret their results as evidence that firms have different risk cultures. In a related study, Balachandran, Kogut, and Harnal (2010) perform a similar analysis of the relation between pay and risk and find a positive and significant correlation.

\subsection{Empirical literature on non-CEO banker pay}

There are very few studies of compensation of lower level bank employees because this data is proprietary. One exception is Agarwal and Ben-David (2012) who studied the results of an experiment that was run at a bank, which for a period of time paid half of its small business loan officers a wage and paid the other half with a wage plus an incentive. They found that the incentive plan increased the loan origination rate by 31 percent and the size of loans by 15 percent. Unfortunately for the bank, the plan also increased the default rate by 28 percent, so the plan was dropped.

Berg, Puri, and Rocholl (2012) studied the data input behavior by loan officers who are paid based on volume. These loan officers entered hard information, that is, nonjudgmental information, into a bank's loan scoring system that determined approval. They find evidence of selective entering of hard information into the scoring system to improve a borrower's chance of approval. Cole, Kanz, and Klapper (2011) ran laboratory experiments on commercial bank loan officers where they varied the connection between compensation and incentives. They found that the compensation structure had a large effect on lending and the quality of the loans.

Finally, Hertzberg, Liberti, and Paravisini (2010) examined the connection between pay, organizational structure, and reporting of information. They examined the use of loan officer rotation at a large international bank and argued that it alleviates incentives to hide the quality of poorly performing loans. In their analysis, the bank's policies effectively tie pay to loans under management, and they argue that the loan rotation along with career concerns mitigate the incentive loan officers have to under report the risk in their portfolio of loans. 


\section{Loan Officer Compensation and Bank Risk}

There is a bank that consists of depositors, equity holders, and a continuum of loan officers of measure one, each of whom has an infinitesimally small effect on the performance of the bank. Each loan officer takes an action $a \in A \subset \Re_{+}$that produces a return $r$ as a function of an idiosyncratic shock and a common shock $\theta$. There is a finite number of possible returns for each loan officer. For most of the analysis there is also a finite number of actions, though in one subsection we allow for a continuum of actions. The common shock can take on a continuum of values over the interval $[0, \Theta]$ and is drawn according to the probability density function $h(\theta)$ with cumulative distribution function $H(\theta)$. The probability of a loan officer's return is written $f(r \mid \theta, a)$ with $\sum_{r} f(r \mid \theta, a) r \geq \sum_{r} f(r \mid \theta, \hat{a}) r$ for all $\theta$ and all $\hat{a}<a$, that is, a loan officer's expected return is increasing in his action. Both shocks occur after the action is taken.

A loan officer's action and idiosyncratic shock are private information, while the common shock is observed by the bank. ${ }^{3}$ A loan officer receives utility from consumption, $c \geq 0$, and action, $a$, of $U(c)-V(a)$, where $U$ is concave and increasing, $U(0) \geq 0$, and $V$ is increasing and weakly convex. Each loan officer has an ex ante reservation utility level of $\bar{U}$.

The bank finances the loan officers' investment projects with an investment of size one. The investment is financed by government insured deposits, $0 \leq D \leq 1$, and equity $1-D$. Because of deposit insurance, depositors receive the face value of deposits at the end of the period no matter how the bank performs. For simplicity, we take the level of deposits as given. ${ }^{4}$

The bank operates in the best interest of the equity holders, so we will often refer to the bank and the equity holders interchangeably. The equity holders are treated as a single

\footnotetext{
${ }^{3}$ We could assume that $\theta$ is not observed by anyone, but as long as the mapping from $a$ to the total return is an invertible function, then $\theta$ could be identified from the contract. For that reason, we simply assume that $\theta$ is public information.

${ }^{4}$ The model can be extended to include franchise value, the value of a bank being a continuing concern. A positive franchise value reduces risk-taking incentives because it is lost in the event of failure. The empirical banking literature finds that franchise value has a significant impact on risk taking. Keeley (1990) argued that the low rate of bank failure pre-1980, before deregulation, was due to banks' incentive to preserve the positive franchise value that came with monopoly profits. The second half of the savings and loan crises is often attributed to savings and loans institutions gambling for resurrection when they had negative franchise value (e.g., White (1991)). Demsetz, Saidenberg, and Strahan (1996) find that franchise value is negatively correlated with risk taking in bank data from the 1990s. We leave franchise value out to keep the problem simpler.
} 
risk-neutral principal with limited liability. The bank receives a total return of $\bar{r}(\theta)$, which is the sum of the loan officers' returns, and pays out funds to depositors and compensation to loan officers. The total compensation bill is $\bar{c}(\theta)$.

The bank's expected profit is

$$
\int_{0}^{\Theta} \max \{\bar{r}(\theta)-\bar{c}(\theta)-D, 0\} h(\theta) d \theta
$$

The total return to the bank is the sum of the individual loan officers' returns, which is

$$
\forall \theta, \quad \bar{r}(\theta)=\sum_{r} f(r \mid \theta, a) r
$$

The bank gives each loan officer the same compensation schedule, $c(r, \theta)$, where $r$ is the return produced by a loan officer. The total compensation bill is then

$$
\forall \theta, \quad \bar{c}(\theta)=\sum_{r} f(r \mid \theta, a) c(r, \theta)
$$

Finally, we assume that in the event of bankruptcy, depositors are paid before loan officers, so if $\bar{r}(\theta)<D$ then $c(r, \theta)=0$.

The problem for the bank is:

\section{Bank Program}

$$
\max _{a, c(r, \theta) \geq 0, \bar{c}(\theta) \geq 0, \bar{r}(\theta)} \int_{0}^{\Theta} \max \{\bar{r}(\theta)-\bar{c}(\theta)-D, 0\} h(\theta) d \theta
$$

subject to $(1),(2)$,

$$
\begin{gathered}
\forall \theta, \quad \bar{c}(\theta) \leq \max \{\bar{r}(\theta)-D, 0\}, \\
\int_{0}^{\Theta} \sum_{r} f(r \mid \theta, a) U(c(r, \theta)) h(\theta) d \theta-V(a) \geq \bar{U}, \\
\int_{0}^{\Theta} \sum_{r} f(r \mid \theta, a) U(c(r, \theta)) h(\theta) d \theta-V(a) \geq \int_{0}^{\Theta} \sum_{r} f(r \mid \theta, \hat{a}) U(c(r, \theta)) h(\theta) d \theta-V(\hat{a}), \quad \forall \hat{a} .
\end{gathered}
$$

Equation (4) limits total compensation to be less than bank revenue, net of payments to depositors. Equation (5) is the participation constraint for a loan officer, and equation (6) is the incentive constraint. 
The piecewise linear objective function and the piecewise linear constraint, (4), make this optimization problem non-differentiable. In order to derive results about compensation from first-order conditions, we consider the subproblem of implementing a given action. For each $a$, there is a $\tilde{\theta}(a)$ such that for all $\theta<\tilde{\theta}(a), \bar{r}(\theta)<D$, that is, the bank is bankrupt and limited liability binds. Note that in these states $c(r, \theta)=\bar{c}(\theta)=0$. Furthermore, because the expected value of a loan officer's return increases with $a, \tilde{\theta}(a)$ is increasing in $a$.

Now consider the subproblem of implementing action $a$ and choosing $c(r, \theta)$ for $\theta \geq \tilde{\theta}(a)$. This subproblem is

\section{Bank Subprogram}

$$
\max _{\forall \theta \geq \tilde{\theta}(a), c(r, \theta) \geq 0, \bar{c}(\theta) \geq 0, \bar{r}(\theta)} \int_{\tilde{\theta}(a)}^{\Theta}(\bar{r}(\theta)-\bar{c}(\theta)-D) h(\theta) d \theta
$$

subject to

$$
\begin{gathered}
\forall \theta \geq \tilde{\theta}(a), \quad \bar{r}(\theta)=\sum_{r} f(r \mid \theta, a) r . \\
\forall \theta \geq \tilde{\theta}(a), \quad \bar{c}(\theta)=\sum_{r} f(r \mid \theta, a) c(r, \theta) . \\
\forall \theta \geq \tilde{\theta}(a), \quad \bar{c}(\theta) \leq \bar{r}(\theta)-D, \\
H(\tilde{\theta}(a)) U(0)+\int_{\tilde{\theta}(a)}^{\Theta} \sum_{r} f(r \mid \theta, a) U(c(r, \theta)) h(\theta) d \theta-V(a) \geq \bar{U}, \\
\int_{\tilde{\theta}(a)}^{\Theta} \sum_{r} f(r \mid \theta, a) U(c(r, \theta)) h(\theta) d \theta-V(a) \\
\geq \int_{\tilde{\theta}(a)}^{\Theta} \sum_{r} f(r \mid \theta, \hat{a}) U(c(r, \theta)) h(\theta) d \theta-V(\hat{a}), \forall \hat{a} .
\end{gathered}
$$

Note that in the incentive constraint, the bankruptcy states on the right-hand side of (12) are a function of $a$ and not the deviating action $\hat{a}$. The bankruptcy states are not defined by a loan officer's deviating action because in equilibrium all loan officers choose the recommended action $a$ and that determines the aggregate return and thus whether there is bankruptcy in state $\theta$. 
The objective function and constraints in the subproblem are differentiable, so we can use the Lagrangian multipliers to characterize an optimal compensation contract. Let $\nu(\theta)$ be the multiplier on (10), $\lambda$ on (11), and $\mu(\hat{a})$ on (12). The first-order condition on $c(r, \theta)$ gives

$$
\frac{h(\theta)+\nu(\theta)}{h(\theta) U^{\prime}(c(r, \theta))}=\lambda+\sum_{\hat{a} \neq a} \mu(\hat{a})\left(1-\frac{f(r \mid \theta, \hat{a})}{f(r \mid \theta, a)}\right),
$$

where $\lambda \geq 0$ and $\mu(\hat{a}) \geq 0$, and when $c(r, \theta)>0$.

There are two cases to consider. First, when $0<\bar{c}(\theta)<\bar{r}(\theta)-D, \nu(\theta)=0$ and the firstorder condition is the same as in the standard moral hazard problem where consumption decreases as the likelihood ratio increases. Second, when $\bar{c}(\theta)=\bar{r}(\theta)-D \geq 0, \nu(\theta)>0$, so the upper bound on the total compensation bill reduces what the bank would pay out if this constraint did not bind.

The subsequent analysis will consider the connection between compensation, $c(r, \theta)$, and the risk profile of the bank. The analysis will also make frequent use of the likelihood ratio in (13). Let $L R(r, \theta, \hat{a} ; a)$ be the likelihood ratio corresponding to the incentive constraint where $a$ is recommended and $\hat{a}$ is the deviating action, that is,

$$
L R(r, \theta, \hat{a} ; a)=\frac{f(r \mid \theta, \hat{a})}{f(r \mid \theta, a)} .
$$

\section{The Importance of Correlation}

In models with deposit insurance and limited liability, the bank's preferences are not aligned with those of society's. The bank's objective function is convex over profits and that can make it willing to undertake negative net present value projects if enough of the downside falls in the range where limited liability is binding. The more leveraged the bank is, the stronger is this effect. In our problem, the bank must use compensation to induce riskaverse loan officers to take actions that generate risk to the bank, if that is, indeed, what the bank wants to do.

As we will see, there is not a direct mapping from the form of loan officer compensation to bank risk. Compensation is important for risk at the individual level, but it is not necessarily important for risk at the bank level. Instead, other factors, like correlation of loan officer 
returns, are far more important. For example, as we will show, if loan officer risk is only idiosyncratic, then bank and social objectives are perfectly aligned.

When there is a common shock in addition to loan officer idiosyncratic risk, then the limited liability distortions can affect bank decisions. In the following analysis, we work through a sequence of functional forms of the production technology, $f(r \mid \theta, a)$, to study connections between compensation and bank risk taking. For each technology, we solve for optimal contracts that implement actions that generate excessive risk and those that do not. We then analyze what information an outsider would need to know to determine whether the compensation arrangement generated excessive risk.

\subsection{Uncorrelated Returns}

Consider the extreme case where there is no correlation in loan officer returns, that is, $f(r \mid a, \theta)=f(r \mid a)$. All risk is idiosyncratic, so the gross return of the bank is a constant

$$
\bar{r}(a)=\sum_{r} f(r \mid a, \theta) r
$$

that depends only on the loan officers' action. Consequently, the bank has no risk.

To implement action $a$, the bank will have to use a compensation contract that satisfies the incentive, participation and limited liability constraints. If there exists a feasible contract then there will be an optimal one and it will cost the bank a total of $\bar{c}(a)$ in compensation payments.

As long as there exists an $a$ such that bank profits are non-negative, the bank chooses an action $a$ that solves

$$
\max \bar{r}(a)-\bar{c}(a)-D
$$

which is the same problem solved by society. Basically, when there is no variation in a bank's total return, limited liability does not distort bank decisions, so compensation is socially optimal and there is no reason to regulate it.

Proposition 1 When loan officer returns are uncorrelated, there is no connection between the form of loan officer compensation and bank risk. 


\subsection{Perfectly Correlated Returns}

Now consider the other extreme case, where loan officer returns are perfectly correlated. In this case, the bank's gross return does vary with $\theta$ and the bank may want to encourage its loan officers to take on risk. Interestingly, loan officer compensation matters for risk, but in a surprising way.

When returns are perfectly correlated, there is no idiosyncratic risk, so the bank can infer a loan officer's action from the common shock, $\theta$, and the loan officer's return $r$. Since the bank essentially knows the action, it can pay each loan officer a wage if his return is what it is supposed to be and zero otherwise. We assume that the zero payment penalty is enough to induce the loan officer to take the recommended action. An alternative way of viewing this contract - and the way we view it - is as a relative performance contract. Each loan

officer's return is compared with that of everyone else's. If his return is the same, he is paid a wage. If it differs, he is paid zero.

The contract has strong incentives in it, but the incentives are not directly tied to his own performance, but instead to how his performance compares with others. In equilibrium, loan officers do not deviate, so what is observed is a compensation contract that is a wage that does not vary with his return, though it may vary with the aggregate return if constraint (10) binds. Consequently, $c(r, \theta)=\bar{c}(\theta)$. Furthermore, from the participation constraint, $(11)$

$$
a=V^{-1}\left(H(\tilde{\theta}(a)) U(0)+\int_{\tilde{\theta}(a)}^{\Theta} h(\theta) U(\bar{c}(\theta))-\bar{U}\right)
$$

The higher the compensation, the harder the loan officer works. Which effort level gives the bank the best opportunity to exploit the safety net depends on the tradeoff between the aggregate return and the aggregate wage bill. Indeed, it is possible that a bank pays a low wage to increase its probability of failure as Figure 1 illustrates. The idea in that figure is that the savings in wage payments increase the bank's profits when it is successful and this benefit outweighs the higher probability of failure, the cost of which, in any case, is borne by the deposit insurer.

To see this more formally, bank profits given action $a$ are 


$$
\begin{aligned}
& \int_{\tilde{\theta}(a)}^{\Theta}(\bar{r}(\theta)-\bar{c}(\theta)-D) h(\theta) d \theta \\
& \quad=\int_{0}^{\Theta}(\bar{r}(\theta)-\bar{c}(\theta)-D) h(\theta) d \theta-\int_{0}^{\tilde{\theta}(a)}(\bar{r}(\theta)-\bar{c}(\theta)-D) h(\theta) d \theta \\
& \quad=\int_{0}^{\Theta}(\bar{r}(\theta)-\bar{c}(\theta)-D) h(\theta) d \theta-\int_{0}^{\tilde{\theta}(a)}(\bar{r}(\theta)-D) h(\theta) d \theta
\end{aligned}
$$

where the last equation holds because for $\theta \in[0, \tilde{\theta}(a)], \bar{c}(\theta)=0$. Substituting in for $\bar{r}(\theta)$ means that profits can also be written

$$
\int_{0}^{\Theta}\left(\sum_{r} f(r \mid \theta, a) r-\bar{c}(\theta)-D\right) h(\theta) d \theta+\int_{0}^{\tilde{\theta}(a)}\left(D-\sum_{r} f(r \mid \theta, a) r\right) h(\theta) d \theta .
$$

To simplify the notation, let $E(\bar{r} \mid a)$ be the expected return produced by the bank; let $E(\bar{c} \mid a)$ be the expected compensation paid out by the bank; and let $z(a)$ be the expected value of the implicit transfers from the deposit insurer to the bank. Formally,

$$
\begin{aligned}
E(\bar{r} \mid a) & =\int_{0}^{\Theta} \sum_{r} f(r \mid \theta, a) r h(\theta) d \theta, \\
E(\bar{c} \mid a) & =\int_{0}^{\Theta} \bar{c}(\theta) h(\theta) d \theta, \\
z(a) & =\int_{0}^{\tilde{\theta}(a)}\left(D-\sum_{r} f(r \mid \theta, a) r\right) h(\theta) d \theta .
\end{aligned}
$$

This last term in bank profits, $z(a)$, is sometimes referred to as the value of the deposit insurance put option because the bank gets to put its losses onto the deposit insurer.

In the rest of this subsection, we make two assumptions. First, we assume that $a$ is chosen from a continuum. This assumption is not essential, but simplifies the analysis. Second, we assume that for all $\theta, \sum_{r} f(r \mid a, \theta) r$ is differentiable, increasing and concave in $a$, that is, there is diminishing returns in expected production given $\theta$. This assumption means that $E(\bar{r} \mid a)$ is differentiable, increasing and concave and that $z^{\prime}(a)<0 .^{5}$

${ }^{5}$ To see this, use Leibniz's rule to get

$$
z^{\prime}(a)=\left[h(\tilde{\theta}(a))\left(D-\sum_{r} f(r \mid \tilde{\theta}(a), a) r\right)\right]-\int_{0}^{\tilde{\theta}(a)} \sum_{r} \frac{\partial f(r \mid \theta, a) r}{\partial a} h(\theta) d(\theta) .
$$

By definition of $\tilde{\theta}(a)$, the term in the brackets is zero. Furthermore, $\forall \theta, \sum_{r} \frac{\partial f(r \mid \theta, a) r}{\partial a}>0$ by assumption, so $z^{\prime}(a)<0$. 
In terms of this new notation, the bank's problem is

$$
\max _{a} E(\bar{r} \mid a)-E(\bar{c} \mid a)-D+z(a)
$$

and the optimal $a$ satisfies

$$
\frac{\partial E(\bar{r} \mid a)}{\partial a}+z^{\prime}(a)=\frac{\partial E(\bar{c} \mid a)}{\partial a}
$$

At a social optimum, society takes into account that $z(a)$ is a transfer. The social optimum is the solution to

$$
\max _{a} E(\bar{r} \mid a)-E(\bar{c} \mid a)-D
$$

so

$$
\frac{\partial E(\bar{r} \mid a)}{\partial a}=\frac{\partial E(\bar{c} \mid a)}{\partial a}
$$

Proposition 2 When loan officer returns are perfectly correlated, if $E(\bar{c} \mid a)$ is increasing and convex in a, then the bank chooses an a that is less than the social optimum.

Proof: Follows directly from $z^{\prime}(a)<0$.

Normally, the monotonicity and convexity of expected pay would not be assumptions requiring any justification. In this model, however, bankruptcy has an effect on the expected wage bill that could violate these assumptions in certain extreme situations. In the absence of bankruptcy, where loan officers receive a constant wage, the level of the wage is a convex function of the effort level. However, with bankruptcy, it is possible that as a increases and the number of bankruptcy states declines, the wage bill will drop (despite the higher effort) because there are fewer states where the loan officers receive zero. This possibility would seem mainly to be an issue when there is a high level of failure and increases in $a$ lead to a substantial marginal decrease in the probability of failure.

The inability to pay employees when there is failure is not in the traditional corporate finance model of risk shifting and the difference illustrates an important point. As long as bank employees do not like risk, they have to be compensated to bear it, and that can make it more expensive for a bank to take risk, which in turn reduces its incentive to exploit risk shifting. Nevertheless, despite these costs, the bank will still not take the socially optimal $a$ 
because of the deposit insurance safety net factor $z(a)$. In the case that we think is relevant most of the time, namely, that the assumptions on expected compensation in Proposition 2 hold, loan officers work less than is socially optimal and a bank fails more frequently than is socially optimal. In this case, the compensation arrangement that encourages excessive risk is a low wage!

\subsection{Partial Correlation}

When loan officer returns are partially correlated, there will be a trade off between the identified effects. The regulator likes diversification because it reduces risk. The bank likes correlation for two reasons, one bad and one good. The bad reason is that correlation allows it to exploit the safety net. The good reason is that correlation relaxes the loan officer's incentive constraint, which reduces the cost to the bank of compensating the loan officers.

\subsection{Identifying Risk-Creating Compensation Contracts}

What these results imply for identifying contracts that generate bank risk depends on what information is known about the bank. If a bank supervisor does not know the correlation of bank returns, then a low wage may signal that the bank's returns are highly correlated and it is trying to shift risk to the deposit insurer. In contrast, if this supervisor knew the correlation, then that information would be used in conjunction with the contract to assess risk. For example, if correlation is low, then the supervisor need not worry about compensation because the bank has limited ability to do risk shifting. In contrast, if correlation is high, then the supervisor needs to worry about risk shifting and should consider the details of the compensation contract. The supervisor will need to develop an understanding

of the technology, $f(r \mid a, \theta)$, and how the compensation contract may generate correlation of returns.

In general, the relationship between compensation and risk depends mainly on the production technology, $f(r \mid a, \theta)$. However, a simple general test for risky compensation contracts can be created directly from the incentive constraints if we assume that there are only two actions for a loan officer to take, one that generates bank risk, $a_{l}$, and one that does not, $a_{h}$, where $V\left(a_{l}\right)<V\left(a_{h}\right)$. The incentive constraint that induces a loan officer to take the risky 


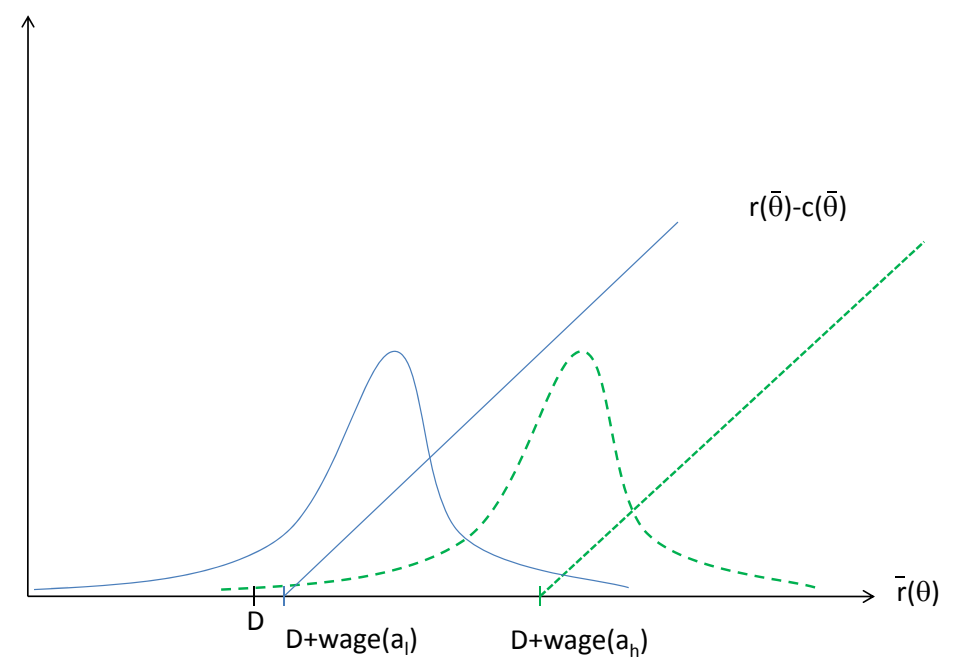

Figure 1: Example of a bank that pays a low wage to increase bank risk when loan officer returns are perfectly correlated. The variable wage $(a)$ is the wage paid to loan officers if $a$ is taken and the bank has produced a high enough return to pay the full wage. The solid line that intercepts the $x$-axis is profits for the bank if $a_{l}$ is taken and if $\bar{r}(\theta) \geq D+$ wage $\left(a_{l}\right)$. (For lower values of $\bar{r}(\theta)$, either all the return net of deposits goes to loan officers or limited liability binds and the bank receives zero profit.) The dashed line that intercepts the $x$-axis is profits if $a_{h}$ is taken and $\bar{r}(\theta) \geq D+$ wage $\left(a_{h}\right)$. The solid curve is the density function of $\bar{r}(\theta)$ when $a_{l}$ is taken and the dashed curve is the corresponding one when $a_{h}$ is taken. For each density, the area under the curve to the left of $D$ is the probability of failure; it is much higher for $a_{l}$. In this figure, the wage to implement $a_{h}$ is so large that the bank receives little profit if its return exceeds $D$. Consequently, the bank prefers to take $a_{l}$, it pays a low wage, and the bank fails more frequently. 
action is

$$
\int_{0}^{\Theta} \sum_{r} f\left(r \mid \theta, a_{l}\right) U(c(r, \theta)) h(\theta) d \theta>\int_{0}^{\Theta} \sum_{r} f\left(r \mid \theta, a_{h}\right) U(c(r, \theta)) h(\theta) d \theta+V\left(a_{l}\right)-V\left(a_{h}\right) .
$$

Because $V\left(a_{l}\right)-V\left(a_{h}\right)<0$, a sufficient condition to implement the risky action is

$$
\int_{0}^{\Theta} \sum_{r} f\left(r \mid \theta, a_{l}\right) U(c(r, \theta)) h(\theta) d \theta>\int_{0}^{\Theta} \sum_{r} f\left(r \mid \theta, a_{h}\right) U(c(r, \theta)) h(\theta) d \theta .
$$

Equation (15) says that if the expected value of compensation — weighted by utility — is higher for the risky action than for the safe action, then the loan officer will take the risky action. It is not a necessary condition; there are compensation arrangements that do not satisfy (18), but still induce the risky action. Nevertheless, equation (15) provides a simple test that identifies a subset of the compensation arrangements that implement risk taking.

This sufficient condition is useful because it does not use knowledge of effort disutility. However, it still requires knowledge of the production function $f(r \mid a, \theta)$. The next section works out the implications of two different specifications of the production function.

\subsection{Example Where Effort Affects Mean of Returns}

In this specification, loan officer effort affects the mean of the return. Each loan officer can take either $a_{l}$ or $a_{h}$, with $0<a_{l}<a_{h}<1$. There are also only two possible returns, failure $(r=0)$ and success $(r=1)$. As before, $\theta$ is the common shock, though now it is restricted to take on values between 0 and 1 . Its mean is $\bar{\theta}$. The probability of success for a loan officer is

$$
f(r=1 \mid \theta, a)=a(\alpha \bar{\theta}+(1-\alpha) \theta) .
$$

The parameter $1-\alpha$ measures the importance of the common shock. For low values of $\alpha$, the return of the bank will vary more with the realization of $\theta$ than for high values of $\alpha{ }^{6}$ Notice that a loan officer's expected return is $a \bar{\theta}$, which does not depend on $\alpha$.

\footnotetext{
${ }^{6}$ To link this production function to the earlier analysis, consider the two extreme values of $\alpha$. If $\alpha=1$ then loan officer returns are uncorrelated. The probability of each loan officer's return being successful, paying $r=1$, is $a \bar{\theta}$. Some loan officers are successful and others are not, but there is no variation in the bank's aggregate return; the bank produces $a \bar{\theta}$ no matter what. If instead $\alpha=0$ then the probability of each loan officer's return being successful is $a \theta$, so the bank's aggregate return depends on the realization of the common shock $\theta$. However, loan officer returns are not perfectly correlated since as long as $0<a \theta<1$ when some loan officers succeed, others will fail.
} 
Compensation is determined by the likelihood ratios. When the recommended action is $a_{h}$, these are

$$
\begin{aligned}
\operatorname{LR}\left(r=1, \theta, a_{l} ; a_{h}\right) & =\frac{a_{l}}{a_{h}}, \\
L R\left(r=0, \theta, a_{l} ; a_{h}\right) & =\frac{1-a_{l}(\alpha \bar{\theta}+(1-\alpha) \theta)}{1-a_{h}(\alpha \bar{\theta}+(1-\alpha) \theta)} .
\end{aligned}
$$

Proposition 3 For the technology specified in (16), at an interior solution, consumption for $r=1$ does not vary with $\theta$ and consumption for $r=0$ increases with $\theta$.

Proof: Likelihood ratios comove with $\theta$ such that

$$
\begin{aligned}
& \frac{\partial L R\left(r=1, \theta, a_{l} ; a_{h}\right)}{\partial \theta}=0 \Rightarrow \frac{\partial c(r=1, \theta)}{\partial \theta}=0 \\
& \frac{\partial L R\left(r=0, \theta, a_{l} ; a_{h}\right)}{\partial \theta}>0 \Rightarrow \frac{\partial c(r=0, \theta)}{\partial \theta}<0 .
\end{aligned}
$$

Figure 2 illustrates the comovement of consumption with $\theta$. Successful loan officers receive a constant level of pay, while unsuccessful ones see their pay drop with the success of the bank. The reason their pay drops is that failure is less likely when there is a high value of $\theta$.

In investment banking and some parts of traditional commercial banking, a substantial fraction of a firm's total compensation bill is often directly tied to performance of the bank or a line of business. For example, investment banks often decide on and report on total compensation as a percentage of revenue.

In this example, the fraction of successful loan officers is $f(r=1 \mid a, \theta)=\bar{r}(\theta)$. Therefore, the share of revenue distributed to loan officers - the only employees in this problem — is

$$
W S(\theta)=\frac{\bar{r}(\theta) c(r=1, \theta)+(1-\bar{r}(\theta)) c(r=0, \theta)}{\bar{r}(\theta)}
$$

An example of a production function that generates perfect correlation of returns, like the case studied in Section 4.2 , is

$$
f(r=1 \mid \theta, a)= \begin{cases}1 & \text { if } a=a_{h}, \theta \geq \theta_{1} \\ 0 & \text { if } a=a_{h}, \theta<\theta_{1} \\ 1 & \text { if } a=a_{l}, \theta<\theta_{1} \\ 0 & \text { if } a=a_{l}, \theta \geq \theta_{1}\end{cases}
$$

where $\theta_{1}$ is a parameter. 


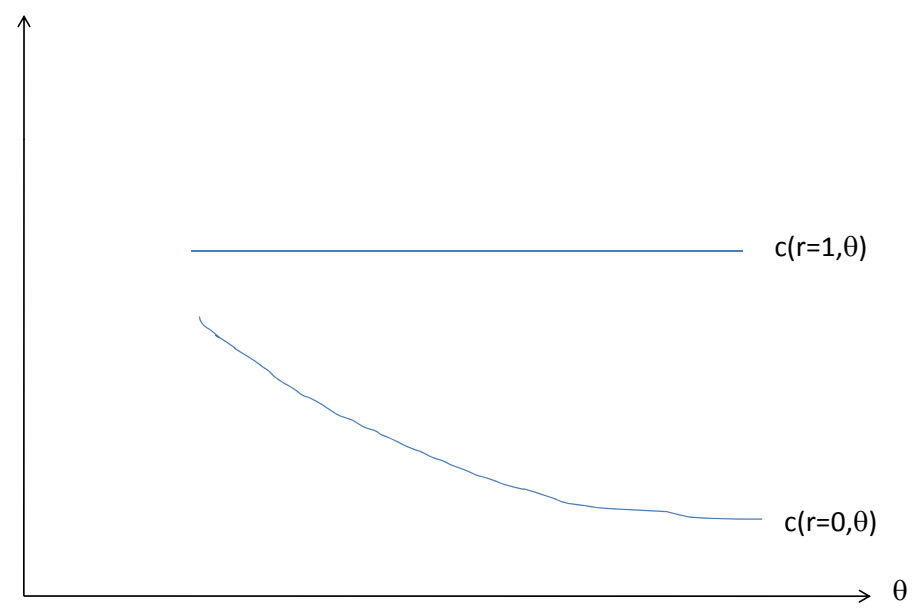

Figure 2: Optimal compensation in example where effort affects the mean of returns, where $a_{h}$ is implemented, and under the assumption of an interior solution. Note that $\bar{r}(\theta)$ is linear in $\theta$, so the $x$-axis is proportional to gross return of the bank. 
for the range of consumption that is interior.

Proposition 4 describes the relationship for this technology.

Proposition 4 For the technology specified in (16) and where consumption is interior

$$
\frac{\partial W S(\theta)}{\partial \bar{r}(\theta)}<0 .
$$

Proof: See the appendix.

In this example, at an optimum the employees' share of income decreases with bank performance. $^{7}$

\subsubsection{Implication for regulation}

In this example, the goal is to prevent the bank from taking the low action, which lowers the mean of the return and increases the probability of failure. For that technology, a pay structure like that in Figure 2 would indicate a prudent compensation scheme. Furthermore, loan officers' share of the bank's revenue would decrease with bank performance.

There are, however, alternative technologies where actions could affect risk in different ways. For example, loan officer actions could directly affect the correlation of the returns. And given our earlier finding that correlation in returns is the big risk to the deposit insurer, we consider an example where a loan officer's action directly affects this variable.

\subsection{Example Where Effort Affects Correlation of Returns}

The production technology is similar to the previous one, but where the loan officer chooses the degree to which his loan is correlated with the bank's performance. The loan officer chooses the correlation of his loan by choosing either a risky, high correlation loan, $\alpha_{l}$, or a safe, low correlation one, $\alpha_{h}$. The agent is not allowed to choose $a$, so for simplicity we drop it from the technology. Formally,

$$
f(r=1 \mid \theta, \alpha)=(\alpha \bar{\theta}+(1-\alpha) \theta)
$$

Recall that $\bar{\theta}=E(\theta)$, so in this example the loan officer's action does not affect the mean of his return, but just its correlation with the performance of the firm. Finally, to reflect the

\footnotetext{
${ }^{7}$ There are other proposed explanations for this behavior, like sorting and retention of workers. See Oyer and Schaefer (2005).
} 
new choice variable, we write the utility function as

$$
U(c)-V(\alpha)
$$

If the bank tries to implement the safe action, $\alpha_{h}$, then the likelihood ratios are

$$
\begin{aligned}
L R\left(r=1, \theta, \alpha_{l} ; \alpha_{h}\right) & =\frac{\alpha_{l} \bar{\theta}+\left(1-\alpha_{l}\right) \theta}{\alpha_{h} \bar{\theta}+\left(1-\alpha_{h}\right) \theta}, \\
L R\left(r=0, \theta, \alpha_{l} ; \alpha_{h}\right) & =\frac{1-\left(\alpha_{l} \bar{\theta}+\left(1-\alpha_{l}\right) \theta\right)}{1-\left(\alpha_{h} \bar{\theta}+\left(1-\alpha_{h}\right) \theta\right)} .
\end{aligned}
$$

Proposition 5 For the technology specified in (17), at an interior solution consumption for $r=1$ decreases with $\theta$ and consumption for $r=0$ increases with $\theta$.

Proof: Likelihood ratios comove with $\theta$ such that

$$
\frac{\partial L R\left(r=1, \theta, \alpha_{l} ; \alpha_{h}\right)}{\partial \theta}>0 \Rightarrow \frac{\partial c(r=1, \theta)}{\partial \theta}<0 .
$$

Similarly,

$$
\frac{\partial L R\left(r=0, \theta, \alpha_{l} ; \alpha_{h}\right)}{\partial \theta}<0 \Rightarrow \frac{\partial c(r=1, \theta)}{\partial \theta}>0 .
$$

Figure 3 illustrates the comovement of consumption with $\theta$. The consumption spread between success and failure declines with bank performance. When a loan officer's return is high and the bank does poorly, the bank rewards the loan officer because his performance is a signal that the loan officer's return was not correlated with everyone else. In contrast, if the loan officer does poorly and the bank does poorly then that is a signal that the loan officer's return is correlated, so the bank punishes him. In general, the bank wants to reward the loan reviewer when the signal indicates no correlation and punish him when the signal indicates correlation.

The effect of relative performance is so strong in this example that for $\theta \geq \bar{\theta}$ the optimal contract is characterized by the loan officer being paid more for $r=0$ than $r=1$ ! This result is specific to this example and need not be the case for technologies that also allow for lower levels of effort that reduce the probability of success. We used this example to starkly illustrate how correlation pushes contracts towards the use of relative performance. ${ }^{8}$

\footnotetext{
${ }^{8} \mathrm{~A}$ guaranteed way to eliminate this result is to allow the loan officer to secretly destroy his own return at no cost as in Innes (1990). This additional source of private information adds an incentive constraint that takes the form $\forall \theta, c(r=0, \theta) \leq c(r=1, \theta)$. The constraint imply that compensation is weakly monotonically increasing in $r$, which is very appealing on empirical grounds. Optimal compensation would look similar to that in Figure 3 for $\theta \leq \bar{\theta}$, but compensation would be a constant for $\theta>\bar{\theta}$.
} 


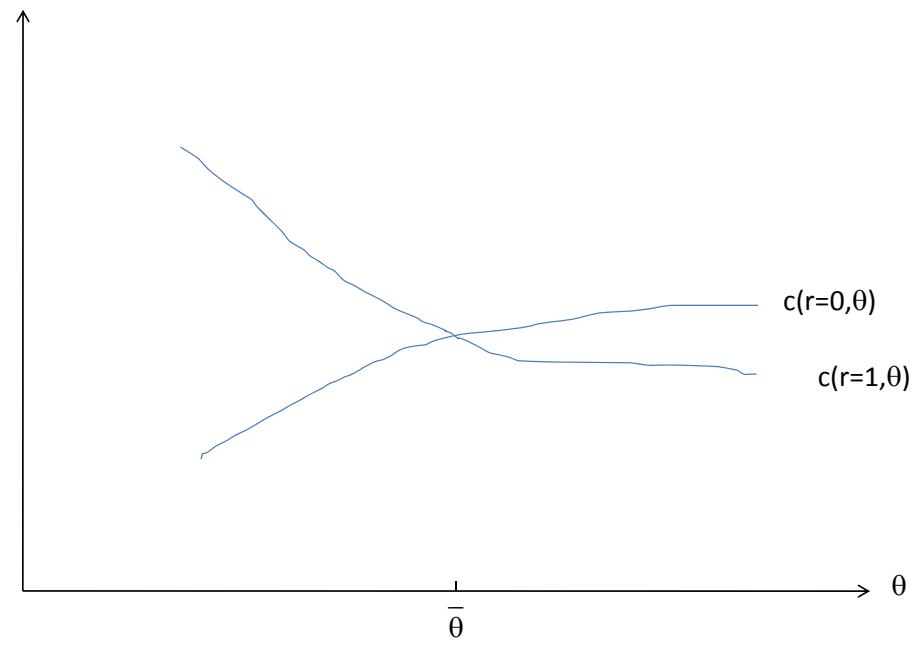

Figure 3: Optimal contract that induces a loan officer to make a low correlation loan. Note that $\bar{r}(\theta)$ is linear in $\theta$, so the $x$-axis also proportional to the total gross return of the bank. 


\subsection{Relative Performance and Risk}

The relative performance contract in Figure 3 reduced bank risk, but there are relative performance contracts in this example that can create bank risk. Intuitively, reversing the slopes of the two compensation schedules in Figure 3 should encourage the high correlation action. Formally, we could derive the comovements based on the likelihood ratios, but it is simpler to just directly consider the incentive constraint that needs to be satisfied to implement the high-correlation action $\alpha_{l}$, which is

$$
\int_{0}^{\Theta}((\bar{\theta}-\theta)(U(c(r=1, \theta))-U(c(r=0, \theta)))) h(\theta) d \theta \leq \frac{V\left(\alpha_{h}\right)-V\left(\alpha_{l}\right)}{\alpha_{h}-\alpha_{l}} .
$$

Equation (18) implies that to induce risk at the bank level, a compensation contract would use;

1. Small pay for performance when the bank performs poorly, that is, for a low $\theta$;

2. High pay for performance when the bank performs well, that is, for a high $\theta$.

Relative performance that increases pay for performance when the bank does well, and decreases it when the bank does poorly, is a type of compensation arrangement that encourages bank risk, by increasing the correlation of bank returns.

It is important to note, however, that it can sometimes be desirable to increase bank risk and that has implications for evaluating the desirability of relative performance contracts. For example, in the technology in Section 4.5, we examined the optimal contract for implementing the high mean action $a_{h}$. As a byproduct of loan officers working $a_{h}$, the variance of the bank's return increased relative to the low action. ${ }^{9}$ Consequently, high bank returns were informative about a loan officer's action and a relative performance contract with increased pay for performance when the bank did well was used. Despite the increased variance in bank returns, the $a_{h}$ action could still be desirable because of its higher expected mean return, which on net can reduce the chance of bankruptcy.

\footnotetext{
${ }^{9}$ More specifically, the variance of the technology in $(16)$ is $\operatorname{Var}(\bar{r}(\theta))=a^{2}(1-\alpha)^{2} \operatorname{Var}(\theta)$, so a higher $a$ increases the variance.
} 


\section{Loan Review and Team Production}

In all but the smallest banks, a bank will typically employ people who monitor lending and risk. For example, in trading, there are risk managers who attempt to monitor and limit trader risk exposure. In mortgage lending, a loan that is originated by a loan officer is evaluated by a loan underwriter who is a different person. In commercial lending, individuals or groups other than the loan officer are required to approve a loan, particularly if it is a larger loan. Loan review is not a new function. For example, Udell (1989) surveyed a large number of Midwestern banks and found extensive use of loan review in the 1980s.

There are several classes of models that are applicable to aspects of loan review. These include models where the loan reviewer audits the loan officer or where the loan reviewer creates a signal that is used to help determine whether the loan is made. To keep the notation and analysis simple, we consider a simpler production function where the loan reviewer's effort is a direct input into production. We also assume that for each loan officer there is one loan reviewer.

The notation is similar to the earlier notation, but with a few additions and slight changes. The loan officer takes an action $\alpha$ and the loan reviewer takes a discrete action $b$. Both are inputs into the production function $g(r \mid \theta, b, \alpha)$. The loan officer's utility function is $U(c)-V(\alpha)$ while the loan reviewer's utility function is $U\left(c_{2}\right)-V(b)$, where $c_{2}$ denote the loan reviewer's compensation. The loan reviewer's reservation utility is $\bar{U}_{2}$.

Compensation for both the loan officer and the loan reviewer can depend on the return and $\theta$, so compensation for the loan officer is $c(r, \theta)$ and compensation for the loan reviewer is $c_{2}(r, \theta)$. The bank's problem with loan review is only slightly different than the earlier problem. It is

\section{Bank's Problem with a Loan Reviewer}

$$
\max _{c(r, \theta) \geq 0, c_{2}(r, \theta) \geq 0, \alpha, b, \bar{c}(\theta) \geq 0, \bar{r}(\theta)} \int_{0}^{\Theta} \max \{\bar{r}(\theta)-\bar{c}(\theta)-D, 0\} h(\theta) d \theta
$$

subject to

$$
\begin{gathered}
\forall \theta, \quad \bar{r}(\theta)=\sum_{r} g(r \mid \theta, b, \alpha) r \\
\forall \theta, \quad \bar{c}(\theta)=\sum_{r} g(r \mid \theta, b, \alpha)\left(c(r, \theta)+c_{2}(r, \theta)\right),
\end{gathered}
$$




$$
\bar{c}(\theta) \leq \max \{\bar{r}(\theta)-D, 0\}
$$

the participation constraints

$$
\begin{gathered}
\int_{0}^{\Theta} \sum_{r} g(r \mid \theta, b, \alpha) U(c(r, \theta)) h(\theta) d \theta-V(\alpha) \geq \bar{U} \\
\int_{0}^{\Theta} \sum_{r} g(r \mid \theta, b, \alpha) U\left(c_{2}(r, \theta)\right) h(\theta) d \theta-V(b) \geq \bar{U}_{2},
\end{gathered}
$$

and the incentive constraints

$$
\begin{aligned}
& \int_{0}^{\Theta} \sum_{r} g(r \mid \theta, b, \alpha) U(c(r, \theta)) h(\theta) d \theta-V(\alpha) \\
& \geq \int_{0}^{\Theta} \sum_{r} g(r \mid \theta, b, \hat{\alpha}) U(c(r, \theta)) h(\theta) d \theta-V(\hat{\alpha}), \quad \forall \hat{\alpha} . \\
& \int_{0}^{\Theta} \sum_{r} g(r \mid \theta, b, \alpha) U\left(c_{2}(r, \theta)\right) h(\theta) d \theta-V(b) \\
& \quad \geq \int_{0}^{\Theta} \sum_{r} g(r \mid \theta, \hat{b}, \alpha) U\left(c_{2}(r, \theta)\right) h(\theta) d \theta-V(\hat{b}), \quad \forall \hat{b} .
\end{aligned}
$$

Notice that in incentive constraint (25) the loan officer takes the loan reviewer's action as given and that in incentive constraint (26) the loan reviewer takes the loan officer's action as given. ${ }^{10}$

We do not write out the bank subproblem, but instead just list the first-order conditions for an interior solution. For loan officers, they are

$$
\frac{1}{U^{\prime}(c(r, \theta))}=\lambda+\sum_{\hat{\alpha}} \mu(\hat{\alpha})\left(1-\frac{g(r \mid \theta, b, \hat{\alpha})}{g(r \mid \theta, b, \alpha)}\right),
$$

where $\lambda$ is the multiplier on the bank subproblem constraint that corresponds to (23) and $\mu(\hat{\alpha})$ on the incentive constraints that correspond to (25). For loan reviewers, they are

$$
\frac{1}{U^{\prime}\left(c_{2}(r, \theta)\right)}=\lambda_{2}+\sum_{\hat{b}} \mu(\hat{b})\left(1-\frac{g(r \mid \theta, \hat{b}, \alpha)}{g(r \mid \theta, b, \alpha)}\right)
$$

where $\lambda_{2}$ is the multiplier on the bank subproblem constraint that corresponds to (24) and $\mu(\hat{b})$ on the incentive constraints that correspond to $(26)$.

\footnotetext{
${ }^{10} \mathrm{An}$ interesting variation to consider is to allow the loan reviewer and loan originator to collude. That would generate a different set of incentive constraints.
} 
For both loan officers and loan reviewers, the first-order conditions show that optimal compensation depends on the return $r$ as a function of the likelihood ratios. The team aspect can be seen in that the action of the other agent affects the likelihood ratio and thus compensation. For loan reviewers, there is the interesting finding that loan reviewers and risk managers should be paid based on the performance of the projects that they monitor. While not surprising from standard incentive theory, it does go against the common perception among bank regulators that risk management employees and those in similar compliance positions should not have their pay tied to the performance of the line of business that they monitor. ${ }^{11}$

\subsection{A Loan Review and Risk Control Example}

This subsection works through a specific functional form to derive some implications of loan reviewer pay for risk control. We build on the same basic production function used in Section 4.6, namely, that

$$
f(r=1 \mid \theta, \alpha)=\alpha \bar{\theta}+(1-\alpha) \theta,
$$

and where the loan officer can make a risky loan, $\alpha_{l}$, or a safe one, $\alpha_{h}$.

The loan reviewer's role is to review a loan originated by the loan officer and then accept or reject it. If accepted the probability of success of the loan is described by (29). If rejected, the bank receives $0<\tilde{r}<1$ with certainty, which reflects the value of the funds being allocated to some low-return safe activity.

Acceptance or rejection is determined probabilistically as a function of the loan type and the loan reviewer's action $b \in\left\{b_{l}, b_{h}\right\}$ with $0<b_{l}<b_{h}<1$. Loan review is not perfect. If the loan officer originates a risky $\alpha_{l}$ loan opportunity then it is rejected with probability $b$. Furthermore, if the loan officer generates a safe $\alpha_{h}$ loan opportunity, then the loan reviewer rejects it with probability $s(b)$, where $s\left(b_{h}\right)<b_{h}$. We also assume that $0<s\left(b_{h}\right)<s\left(b_{l}\right)<1$, which means that if the loan reviewer works harder, he rejects risky loans more frequently and safe loans less frequently.

There are three possible outcomes:

\footnotetext{
${ }^{11}$ These kind of concerns seem driven by fears of collusion between the loan officers and the loan review function.
} 
1. The loan is not rejected and $r=0$;

2. The loan is not rejected and $r=1$;

3. The loan is rejected, so $r=\tilde{r}$.

The production function is

$$
\begin{aligned}
g\left(r=0 \mid \theta, b, \alpha_{l}\right) & =(1-b) f\left(r=0 \mid \theta, \alpha_{l}\right) \\
g\left(r=1 \mid \theta, b, \alpha_{l}\right) & =(1-b) f\left(r=1 \mid \theta, \alpha_{l}\right) \\
g\left(r=\tilde{r} \mid \theta, b, \alpha_{l}\right) & =b . \\
g\left(r=0 \mid \theta, b, \alpha_{h}\right) & =(1-s(b)) f\left(r=0 \mid \theta, \alpha_{h}\right) \\
g\left(r=1 \mid \theta, b, \alpha_{h}\right) & =(1-s(b)) f\left(r=1 \mid \theta, \alpha_{h}\right) \\
g\left(r=\tilde{r} \mid \theta, b, \alpha_{h}\right) & =s(b) .
\end{aligned}
$$

If the bank is trying to implement the safe action, $\alpha_{h}$, then for loan officers the likelihood ratios are

$$
\begin{aligned}
L R\left(r=1, \theta, b, \alpha_{l} ; \alpha_{h}\right) & =\frac{(1-b) f\left(r=1 \mid \theta, \alpha_{l}\right)}{(1-s(b)) f\left(r=1 \mid \theta, \alpha_{h}\right)}, \\
L R\left(r=0, \theta, b, \alpha_{l} ; \alpha_{h}\right) & =\frac{(1-b) f\left(r=0 \mid \theta, \alpha_{l}\right)}{(1-s(b)) f\left(r=0 \mid \theta, \alpha_{h}\right)}, \\
L R\left(r=\tilde{r}, \theta, b, \alpha_{l} ; \alpha_{h}\right) & =\frac{b}{s(b)} .
\end{aligned}
$$

The comparative statics for $r=0$ and $r=1$ are qualitatively the same as in the earlier analysis of Section 4.6. For $r=\tilde{r}$, the loan officer receives a fixed level of compensation that does not depend on bank performance, at least for interior solutions. This amount could be interpreted as a fixed retainer for the loan officer, which is common in sales jobs.

For loan reviewers, if the bank is implementing the safe action, $\alpha_{h}$, and the high-quality loan review, $b_{h}$, then the likelihood ratios are

$$
\begin{aligned}
& L R\left(r=1, \theta, b_{l}, \alpha_{h} ; b_{h}\right)=\frac{1-s\left(b_{l}\right)}{1-s\left(b_{h}\right)}, \\
& L R\left(r=0, \theta, b_{l}, \alpha_{h} ; b_{h}\right)=\frac{1-s\left(b_{l}\right)}{1-s\left(b_{h}\right)}, \\
& L R\left(r=\tilde{r}, \theta, b_{l}, \alpha_{h} ; b_{h}\right)=\frac{s\left(b_{l}\right)}{s\left(b_{h}\right)} .
\end{aligned}
$$


Loan reviewer compensation depends on whether a loan is made, but, if it is made, not on how it performs. ${ }^{12}$ Furthermore, because $\frac{s\left(b_{l}\right)}{s\left(b_{h}\right)}>\frac{1-s\left(b_{l}\right)}{1-s\left(b_{h}\right)}$, pay is lower if the loan reviewer rejects the loan. The reason for this result is when the loan officer takes the safe action, the rejection rates are higher if the loan reviewer deviates.

Pay is informative in this example, but there is a much simpler way to evaluate the risk in the bank's lending activities. In this example, simply evaluate the loan rejection rates. There are four such possible rates, $b_{l}, b_{h}, s\left(b_{l}\right)$, and $s\left(b_{h}\right)$ and they contain all the information a bank supervisor needs to determine the amount of risk the bank is taking in the form of $\alpha$.

While the simplicity of monitoring loan rejection rates is specific to this example, the analysis does point to an alternative strategy to regulating compensation for controlling risk. The loan review process could be evaluated to determine how well it identifies and manages risk. Indeed, an important activity of bank supervision is to evaluate the "controls," that is, the quality of the processes used by banks to approve loans and manage risk, and in this model that would be reflected by evaluating rejection rates as well as the quality of the loan reviewer's assessment.

\section{Conclusion}

This paper worked through several organizational models of banker incentive compensation. We found that the contribution of banker pay to bank risk depends on the amount of correlation in loan officer returns. If returns are uncorrelated, the form of banker pay is irrelevant. If they are correlated, then low wages could be risk creating. When the correlation of returns is endogenous, the structure of relative performance contracts greatly influences risk. Pay for individual performance that increases with total bank performance was a source of bank risk. A sufficient condition for a compensation arrangement to create bank risk was provided.

A model of an organization with monitoring and controls in the form of loan review was also introduced. The analysis suggested that monitoring and evaluating the loan review

\footnotetext{
${ }^{12}$ As noted in the previous analysis, this is not true in general. It is true in this example because loan review probabilistically determines acceptance or rejection, so that decision is what contains information on the loan reviewer's action.
} 
process can be an effective alternative to regulating compensation for controlling bank risk and that paying risk managers for the performance of the employees they monitor does not necessarily create risk.

More generally, the analysis illustrated an important principle of organizational economics: Compensation and its effect on the performance of a bank depend on the way that the bank organizes its production. Looking at pay in isolation without considering the loan officers' production function and the effects of the bank's monitoring and controls could not only lead to bans on compensation arrangements that do not necessarily create risk, but could also permit forms of compensation that in isolation look harmless, but instead, generate excessive risk.

\section{A Proofs}

\section{Proof of Proposition 4}

Let $W S(\theta)$ be the loan officers' share of total revenue. Also, recall that $\bar{r}(\theta)$ is not only the total revenue, but also the fraction of loan officers who produce the high return of one. First,

$$
\begin{aligned}
W S(\theta)=\frac{\bar{c}(\theta)}{\bar{r}(\theta)} & =\frac{\bar{r}(\theta) c(r=1, \theta)+(1-\bar{r}(\theta)) c(r=0, \theta)}{\bar{r}(\theta)} \\
& =c(r=1, \theta)+\frac{c(r=0, \theta)}{\bar{r}(\theta)}-c(r=0, \theta) .
\end{aligned}
$$

Differentiating with respect to total revenue gives

$$
\frac{d W S(\theta)}{d \bar{r}(\theta)}=\frac{\partial c(r=1, \theta)}{\partial \bar{r}(\theta)}+\frac{\bar{r}(\theta) \frac{\partial c(r=0, \theta)}{\partial \bar{r}(\theta)}-c(r=0, \theta)}{\bar{r}(\theta)^{2}}-\frac{\partial c(r=0, \theta)}{\partial \bar{r}(\theta)} .
$$

Note: $\frac{\partial c(r=1, \theta)}{\partial \bar{r}(\theta)}=0$ because $\frac{\partial c(r=1, \theta)}{\partial \theta}=0$. Therefore,

$$
\frac{d W S(\theta)}{d \bar{r}(\theta)}=\frac{\partial c(r=0, \theta)}{\partial \bar{r}(\theta)}\left(\frac{1}{\bar{r}(\theta)}-1\right)-\frac{c(r=0, \theta)}{\bar{r}(\theta)^{2}}<0 .
$$

The term $\frac{\partial c(r=0, \theta)}{\partial \bar{r}(\theta)}=\frac{\partial c(r=0, \theta)}{\partial \theta} \frac{\partial \theta}{\partial \bar{r}(\theta)}<0$ because $\frac{\partial c(r=0, \theta)}{\partial \theta}<0$ and $\frac{\partial \theta}{\partial \bar{r}(\theta)}>0$. Furthermore, $\bar{r}(\theta)<1$, so the first term is negative. The second term is also negative, so the sum is negative. 


\section{References}

[1] Agarwal, Sumit, and Itzhak Ben-David. "Do Loan Officers' Incentives Lead to Lax Lending Standards." Fisher College of Business Working Paper No. 2012-03-007, August 2012.

[2] Balachandran, Sudhakar, Bruce Kogut, and Hitesh Harnal. "The Probability of Default, Excessive Risk, and Executive Compensation: A Study of Financial Services Firms from 1995 to 2008." Manuscript, May 2010.

[3] Benston, George J., and Jocelyn D. Evans. "Performance Compensation Contracts and CEO's Incentives to Shift Risk to Debtholders: An Empirical Analysis." Journal of Economics and Finance, vol. 30 (2006), pp 70-92.

[4] Berg, Tobias, Manu Puri, and Jörg Rocholl. "Loan Officer Incentives and the Limits of Hard Information." Manuscript, March 2012.

[5] Bolton, Patrick, Hamid Mehran, and Joel Shapiro. "Executive Compensation and Risk Taking." Federal Reserve Bank of New York Staff Report 456, June 2010.

[6] Cheng, Ing-Haw, Harrison Hong, and Jose Scheinkman. "Yesterday's Heroes: Compensation and Creative Risk-Taking." NBER Working Paper No. 16176, July 2010.

[7] Cole, Shawn, Martin Kanz, and Leora Klappe. "Incentivizing Calculated Risk-Taking." Manuscript. November 2, 2011.

[8] Crawford, Anthony J., John R. Ezzell, and James A. Miles. "Bank CEO Pay-Performance Relations and the Effects of Deregulation." Journal of Business, vol. 68 (1995), pp 231256.

[9] Demsetz, Rebecca S., Marc R. Saidenberg, and Philip E. Strahan, "Banks with Some-

thing to Lose: The Disciplinary Role of Franchise Value." Federal Reserve Bank of New York Economic Policy Review, vol. 2 (1996), pp 1-14.

[10] Fahlenbrach, Rüdiger, and René M. Stulz. "Bank CEO Incentives and the Credit Crisis." Journal of Financial Economics, vol. 99 (2011), pp 11-26. 
[11] Federal Register, "Guidance on Sound Incentive Compensation Practices." Vol. 75 (122), June 25, 2010.

[12] Financial Stability Forum, "FSF Principles for Sound Compensation Practices." April 2, 2009 .

[13] Flannery, Mark. "Capital Regulation and Insured Banks' Choice of Individual Loan Default Risk." Journal of Monetary Economics, vol. 24 (1989), pp 235-258.

[14] Furlong, Federick T., and Michael C. Keeley. "A Reexamination of Mean-Variance Analysis of Bank Capital Regulation." Journal of Banking and Finance, vol. 14 (1990), pp 69-84.

[15] Hertzberg, Andrew, Jose Maria Liberti,and Daniel Paravisini. "Information and Incentives Inside the Firm: Evidence from Loan Officer Rotation." Journal of Finance, vol. 65 (2010), pp 795-828.

[16] Houston, Joel F., and Christopher James. "CEO Compensation and Bank Risk: Is Compensation in Banking Structured to Promote Risk Taking?" Journal of Monetary Economics, vol. 36 (1995), pp 405-431.

[17] Innes, Robert D. "Limited Liability and Incentive Contracting with Ex-ante Action Choices." Vol. 52 (October 1990), pp 45-67.

[18] Jarque, Arantxa, and Edward Simpson Prescott. "Optimal Bonuses and Deferred Pay for Bank Employees: Implications of Hidden Actions with Persistent Effects in Time." Federal Reserve Bank of Richmond Working Paper 10-16, October 2010.

[19] Jensen, Michael C., and Kevin J. Murphy. "Performance Pay and Top Management Incentives." Journal of Political Economy, vol. 98 (1990), pp 225-264.

[20] John, Kose, Anthony Saunders, and Lemma W. Senbet. "A Theory of Bank Regulation and Management Compensation." Review of Financial Studies, vol. 13 (2000), pp 95-125.

[21] Kareken, John H., and Neil Wallace. "Deposit Insurance and Bank Regulation: A Partial-Equilibrium Exposition." Journal of Business, vol. 51 (1978), pp 413-438. 
[22] Keeley, Michael C. "Deposit Insurance, Risk, and Market Power in Banking." American Economic Review, vol. 80 (1990), pp 1183-1200.

[23] Kim, Daesik, and Anthony M. Santomero. "Risk in Banking and Capital Regulation." Journal of Finance, vol. 43 (1988), pp 1219-1233.

[24] Marshall, David A., and Edward Simpson Prescott, "Bank Capital Regulation With and Without State-Contingent Penalties." Carnegie-Rochester Conference Series on Public Policy, vol. 54 (2001), pp 139-184.

[25] Marshall, David A., and Edward Simpson Prescott, "State-Contingent Bank Regulation with Unobserved Actions and Unobserved Characteristics." Journal of Economic Dynamics \& Control, vol. 30 (2006), pp 2015-2049.

[26] Merton, Robert C. "An Analytical Derivation of the Cost of Deposit Insurance and Loan Guarantees: An Application of Modern Option Pricing Theory." Journal of Banking \& Finance, vol. 1 (1977), pp 2-11.

[27] Phelan, Christopher. "Incentive Compensation in the Banking Industry: Insights from Economic Theory." Federal Reserve Bank of Minneapolis, Economic Policy Paper 09-1, December, 2009.

[28] Udell, Gregory F. "Loan Quality, Commercial Loan Review and Loan Officer Contracting." Journal of Banking and Finance, vol. 13 (1989), pp 367-382.

[29] White, Lawrence J. The SËL Debacle. Oxford University Press, New York, 1991. 